\title{
Emphysematous epididymo-orchitis
}

Sir,

We read with a great deal of interest the article by Mandava et al. describing the imaging features of emphysematous epididymo-orchitis ${ }^{[1]}$ and found it to be informative and excellently written. However, we would like to make a few contributions.

In the manuscript, the authors describe "emphysematous epididymo-orchitis" to have been reported in only two cases prior to the present case. A search on Pubmed, however, reveals a total of five cases including the present one. ${ }^{[2,3]}$ Yet another case was published by Gretchen. ${ }^{[4]}$

Secondly, we would like to understand the indication of MRI in the present case. Since the diagnosis was fairly established on USG and further confirmed on CT, the need to perform a battery of investigations needs to be better explained. Besides, the patient presented with acute scrotal pain and MRI, being a lengthy procedure, is typically not preferred (ACR Appropriateness Criteria ${ }^{\circledR}$ acute onset of scrotal pain - without trauma, without antecedent mass).

Finally, the differential diagnosis should be case-relevant. Torsion of testis is extremely rare in old age. The reported case here is a 51-year-old male, torsion of testis in whom is highly unlikely.

We conclude by once again commending the authors for an excellent article. However, it would be of enormous help if the authors could clarify certain doubts we had.

\section{Author's reply}

We have considered and ruled out the diagnosis of Fournier's gangrene (FG) in this case.

FG is defined as a life-threatening necrotizing fasciitis of the perineal, genital, and perianal regions, which leads to thrombosis of the small subcutaneous vessels and results in the development of gangrene of the overlying skin..$^{[1,2]}$ The basic pathological process in FG is necrotizing fasciitis, and infection in FG tends to spread along the fascial planes (Colles fascia, Scarpa fascia, Dartos fascia, and Buck fascia). ${ }^{[3,4]}$ In $90 \%$ of cases of FG, the source of infection may be colorectal, urologic, or cutaneous. ${ }^{[2,5]}$ The infection commonly starts as a cellulitis adjacent to the portal of entry, depending on the source of infection, commonly in the perineum or perianal region. ${ }^{[4]}$ Infection arising from the
Yashant Aswani, Karan M Anandpara

Department of Radiodiagnosis, Seth Gordhandas Sunderdas Medical College and King Edward Memorial Hospital, Mumbai, Maharashtra, India E-mail: aswaniyashant@gmail.com

\section{References}

1. Mandava A, Rao RP, Kumar DA, Naga Prasad IS. Imaging in emphysematous epididymo-orchitis: A rare cause of acute scrotum. Indian J Radiol Imaging 2014;24:306-9.

2. Natarajan V, Burgess NA, Gaches CG, Ball RY. Emphysematous infarction of the testis following epididymo-orchitis. Br J Urol 1995;76:270-1.

3. Hegde RG, Balani A, Merchant SA, Joshi AR. Synchronous infection of the aorta and the testis: Emphysematous epididymo-orchitis, abdominal aortic mycotic aneurysm, and testicular artery pseudoaneurysm diagnosed by use of MDCT. Jpn J Radiol 2014;32:425-30.

4. Gretchen AW. Gooding. Ultrasound in acute testicular disease. Emerg Radiol 1999;6:313-5.

\begin{tabular}{|l|l|}
\hline \multicolumn{2}{|c|}{ Access this article online } \\
\hline Quick Response Code: & \\
\hline & Website: \\
\hline
\end{tabular}

anal triangle can spread along the Colles fascia (superficial perineal fascia) and progress anteriorly along the Dartos fascia to involve the scrotum and penis..$^{[4,6]}$ The testes and epididymides are normal in FG as a result of deriving their blood supply from the testicular arteries, which originate directly from the aorta. ${ }^{[4,7]}$ Involvement of the testis suggests retroperitoneal origin or spread of infection. ${ }^{[4]}$ Testicular necrosis in FG is an indicator of severe disease, as this points to retroperitoneal sepsis which causes thrombosis of the testicular blood vessels. ${ }^{[8]}$ Systemic findings in FG include leukocytosis, dehydration, tachycardia, thrombocytopenia, anemia, hypocalcemia, and hyperglycemia, and the patient also has pronounced systemic signs, usually out of proportion to the local extent of the disease. ${ }^{[4-6]} \mathrm{FG}$ tends to be polymicrobial in nature with an average of more than 
three organisms cultured per patient. ${ }^{[1,2,5,6,9,10]}$ Recently, scoring systems based on laboratory studies have been described to facilitate and expedite the diagnosis of necrotizing fasciitis. ${ }^{[10]}$ Wall and colleagues have found that patients with necrotizing infection had either a white blood cell count of 15,400 cells $/ \mathrm{mm}^{3}$ or a sodium level of $135 \mathrm{mmol} / \mathrm{l}$ on admission to the hospital and these values had a $80 \%$ positive and negative predictive values. ${ }^{[11]}$ Wong and colleagues described a score that they called the "Laboratory Risk Indicator for Necrotizing Fasciitis," based on six variables [C-reactive protein, WBC (cells $\left./ \mathrm{mm}^{3}\right)$, hemoglobin $(\mathrm{g} / \mathrm{dl})$, sodium $(\mathrm{mmol} / \mathrm{l})$, creatinine $(\mathrm{mcg} / \mathrm{l})$, glucose $(\mathrm{mmol} / \mathrm{l})]$. A score of 6 has a positive predictive value of $92 \%$ and a negative predictive value of $96 \%$ for necrotizing fasciitis. ${ }^{[12]}$ The diagnostic ultrasound findings consistent with necrotizing fasciitis include fascial and subcutaneous tissue thickening, abnormal fluid accumulation in the deep fascia layer, and, in advanced cases, subcutaneous air. ${ }^{[13,9]}$ In FG, sonographic evaluation of the scrotum, scrotal contents, and surrounding structures shows a thickened and edematous scrotal wall, gas within the scrotal wall, peritesticular fluid, and the testes and epididymides of normal size and architecture. ${ }^{[4,6,7,14]}$ The CT features of FG include soft-tissue thickening and inflammation, asymmetric fascial thickening, any coexisting fluid collection or abscess, fat stranding around the involved structures, and subcutaneous emphysema. ${ }^{[4,6]}$ Literature reports suggest that MRI has a role in the diagnosis of necrotizing fasciitis. MRI has a sensitivity of $90-100 \%$, but a specificity of only $50-85 \%$ for detecting necrotizing fasciitis, and findings that are specific include hyperintense signal on T2-weighted images at the deep fascia and within muscles and peripheral enhancement on contrast-enhanced T1-weighted images..$^{[10,15]}$

Clinical diagnoses in FG are based on general appearance, medical history, physical examination, laboratory data, and signs and symptoms upon admission. ${ }^{[7]}$

In our case, the primary pathology involved testis and epididymis with very small focal involvement of the deeper layers of scrotum adjacent to the right testis, with emphysematous changes. In all the previous cases reported, testicular involvement in FG was secondary to peritoneal and perineal infections and spread through fascia, which was not seen in our case. By definition, the basic pathological process in FG, i.e. necrotizing fasciitis, was absent in this case. No abdominal, perineal, or retroperitoneal infection was found in the present case. The superficial and deep perineal fascia including Colles fascia, Scarpa fascia, Dartos fascia, or Buck fascia, which are the paths of spread in FG, were normal. There were no systemic symptoms in the present case except for pyrexia and tachycardia and the clinical findings were limited to testis, epididymis, and small area of adjacent scrotal wall. Blood, urine, and postoperative specimen cultures were negative in this case.
In our case, the lab findings showed a random blood sugar of $155 \mathrm{mg} / \mathrm{dl}$, glycosylated hemoglobin of 7.4, leukocyte (WBC) count of 14,800 cells per $\mathrm{mm}^{3}$, and normal serum urea, creatinine, and electrolyte levels. Scoring systems based on laboratory studies were negative for necrotizing fasciitis in the present case. Laboratory Risk Indicator for Necrotizing Fasciitis in our case was zero. The imaging criteria diagnostic of FG in the perineum were not seen in the present case. The epididymis and testis were completely involved, and the CT and MR images show that the entire epididymis and testis were replaced by air [Figures 4 and 5]. The only subcutaneous pathology was focal in the deep layers of scrotum adjacent to the right testis and the superficial layers were spared [Figure 4]. Abdominal imaging in both CT and MRI was normal. Due to limitation in the number of images accepted by the journal and normalcy of findings, abdominal sections of the MDCT were not provided. MR images in the present case showed air in the right testis, epididymis, and scrotal wall, which was hypointense on all sequences suggestive of emphysematous epididymo-orchitis. We agree with the observation that MRI is time consuming and not required in all the cases. This was the first case of emphysematous epididymo-orchitis we encountered in our hospital. CT and MRI were done on the same day to confirm the diagnosis, see the extent of soft tissue involvement, and rule out FG. The patient was taken up for surgery on the same day evening.

\section{Conclusion}

Based on the signs and symptoms upon admission, clinical features, pathological abnormality, laboratory data, radiological findings, and rapid response to the management, we ruled out the diagnosis of FG (necrotizing fasciitis) in the present case and we reaffirm the diagnosis of emphysematous epididymo-orchitis.

Anitha Mandava, R Prabhakar Rao, D Anjani Kumar ${ }^{1}$, I Shiva Naga Prasad²

Departments of Radiodiagnosis and 'Surgery, South Central Railway Hospital, 'Department of Radiodiagnosis, Yashoda Hospital, Secunderabad, Telangana, India.

E-mail: kanisri@gmail.com

\section{References}

1. Smith GL, Bunker CB, Dinneen MD. Fournier's gangrene. Br J Urol 1998;81:347-55.

2. Cubilla A, Chaux A. Penis and scrotum. Infectious disorders. Fournier's gangrene. Available from: http://www.pathologyoutlines. com/topic/penscrotumfournier.html. [Last accessed on 2014 Aug 27].

3. Eke N. Fournier's gangrene: A review of 1726 cases. Br J Surg 2000;87:718-28.

4. Levenson RB, Singh AK, Novelline RA. Fournier gangrene: Role of imaging. Radiographics 2008;28:519-28.

5. Thwaini A, Khan A, Malik A, Cherian J, Barua J, Shergill I, et al. Fournier's gangrene and its emergency management. Postgrad Med J 2006;82:516-9. 
6. Rajan DK, Scharer KA. Radiology of fournier's gangrene. AJR Am J Roentgenol 1998;170:163-8.

7. Chawla SN, Gallop C, Mydlo JH. Fournier's gangrene: An analysis of repeated surgical debridement. Eur Urol 2003;43:572-5.

8. Eke N. Fournier's gangrene, still an enigma. J Postgrad Med 2008;54:83-4.

9. Uluğ M, Gedik E, Girgin S, Celen MK, Ayaz C. The evaluation of microbiology and Fournier's gangrene severity index in 27 patients. Int J Infect Dis 2009;13:e424-30.

10. Sarani B, Strong M, Pascual J, Schwab CW. Necrotizing fasciitis: Current concepts and review of the literature. J Am Coll Surg 2009;208:279-88.

11. Wall DB, de Virgilio C, Black S, Klein SR. Objective criteria may assist in distinguishing necrotizing fasciitis from nonnecrotizing soft tissue infection. Am J Surg 2000;179:17-21.

12. Wong $\mathrm{CH}$, Khin LW, Heng KS, Tan KC, Low CO. The LRINEC (Laboratory risk indicator for necrotizing fasciitis) score: A tool for distinguishing necrotizing fasciitis from other soft tissue infections. Crit Care Med 2004;32:1535-41.
13. Coulier B, Ramboux A, Maldague P. Emphysematous epididymitis as presentation of unusual seminal vesicle fistula secondary to sigmoid diverticulitis: Case report. Abdom Imaging 2005;30:113-6.

14. Kane CJ, Nash P, McAninch JW. Ultrasonographic appearance of necrotizing gangrene: Aid in early diagnosis. Urology 1996;48:142-4.

15. Schmid MR, Kossmann T, Duewell S. Differentiation of necrotizing fasciitis and cellulitis using MR imaging. AJR Am J Roentgenol 1998;170:615-20.

Access this article online

Quick Response Code:

Website:

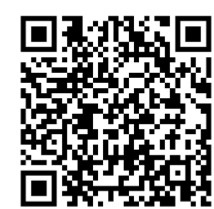

